\title{
The Role and Difficulties of Non-Governmental Organizations (Ngo)'s in Kurdistan Region of Iraq / Erbil between 2014 and 2017: A Case Study of Peace Wind Japan
}

\author{
Karwan Talaat Rashid ${ }^{1} \&$ Yousif Maghdid Qadir ${ }^{2}$ \\ ${ }^{1}$ Business and Management Department, Faculty of Administrative Sciences and \\ Economics, Tishk International University, Erbil, Iraq \\ ${ }^{2}$ Independent Researcher \\ Correspondence: Karwan Talaat Rashid, Tishk International University, Erbil, Iraq. \\ Email: karwan.talaat@ishik.edu.iq
}

Doi: 10.23918/ejmss.v1i2p21

\begin{abstract}
Syria and Iraq have been affected by ISIS conflict since (20142017). The displaced refugees/asylums have been coming to the Kurdistan region of Iraq. The governmental support was not enough to provide adequate services to the refugees, and it has come to rely on NonGovernmental Organizations (NGOs) to provide services. The study was conducted to examine the role and existing difficulties, particularly in KRI - Erbil. The data were collected from Peace Wind Japan (PWJ) organization, and the primary data were obtained through interviews with three of the PWJ employees. According to the results, the role of NGOs was effective in a positive way. Also, NGO was considered adequate in its activities. This analytical study identifies the impact of the NGOs with emphasis on human activities especially focusing on their field activities during the years (2014-2017).
\end{abstract}

Keywords: Peace Wind Japan (PWJ), Non-Governmental Organization (NGO), Kurdistan Region of Iraq, Internal and international Displaced People 


\section{EJMSS}

\section{Eurasian Journal of Management \& Social Sciences}

\section{Introduction}

In the world complexity, the Non-Governmental Organization (NGO) has a very powerful impact on social and humanitarian development. As there is no profit organization (providing various services) which can protect humanitarian life. However, worldwide there are a large number of Non-Governmental Organizations (NGOs) in existence, with different motives and approaches which maintain a distance with governmental procedures. Furthermore, NGO is a voluntary citizen's group organized at the international or local level that offers to serve in specific issues including human rights, health, environment, etc. NGOs differ in their identities which describes their existence, for example, of them receive funding by the developed countries, corporates, companies, and societies. Today, the crisis has extended to the whole of middle east countries among which many regions are located within the Kurdistan region of Iraq i.e. Mosul, Kirkuk, and Duhok (40 kilometers away from Erbil) which were affected by ISIS war. Moreover, there was a large number of refugees who escaped from their homeland to come to Kurdistan region of Iraq so that they can protect their children, families, and parents. The existence of most of the NGOs is the result of such a crisis in the region. These NGOs play an important role in providing shelter, food, and other basic amenities required for their survival (Spark, 2018). This analytical study identifies the impact of NGOs with emphasis on human activities especially focusing on their field activities during the years (20142017). These NGOs are serving and accommodating the needy people who were displaced by any reason or were facing any threat to their life. The NGOs also involved the local people as volunteers (Dinish Refugee Council, 2015). The other important point is that this particular revelation for KRG (Kurdistan Region Government) made them to highlight the role of NGO's to make better improvement, development, and provide support. There are different support sources for different types of NGOs as per their requirements. In the current research, the role of PWJ has been focused which serves the internally and externally displaced refugees and asylum seekers from Syria and Iraq. PWJ decreased the pressures and significantly supported the Kurdistan region of Iraq which was facing the humanitarian and financial crisis due to the ISIS war.

PWJ became a great cooperator with the government for emergency humanitarian relief, reconstruction, and development assistance, in the reaction to the influx of people coming from the conflict zones of Syria, a neighbor of Kurdistan Iraq. In 2012, Peace Winds Japan started distributions of emergency humanitarian relief goods as well as nonfood items and 


\section{EJMSS Eurasian Journal of Management \& Social Sciences}

provided the necessities to the refugees in DOMIZ camp in Duhok governorate. This elucidates the importance of PWJ as an NGO in KRG.

\subsection{Research Objectives}

1. To find out the effectiveness of Peace Wind Japan programs towards internally displaced people from Syria in Kurdistan.

2. To find out the reason why Peace Wind Japan choose to focus on internal and internationally displaced people in Syria living in camps and if it was a good strategical choice.

3. To understand the difficulties which Peace Wind Japan faced while implementing their programs.

4. To understand what is required to improve their programs.

\subsection{Research Questions}

1. How Peace Winds Japan NGOs affected internally displaced people in Syria during 2014-2017?

2. Why did Peace Wind Japan concentrate more on internally displaced people in Syria living in camps rather than the ones outside the camps?

3. What are the difficulties Peace Winds Japan NGO faced during their operation in Kurdistan between (2014-2017)?

4. What can they improve in their programs?

\section{Literature Review}

\subsection{Non-Governmental Organizations}

In the era of globalization, the main motive of the majority of the NGOs is to start operations at an international platform to receive the fundings from donor agencies. Although there were some controversies as well regarding these kinds of fundings but during the 1960s and 70s, these NGOs already contributed significantly towards political resistance, social welfare, and grassroots movements. However, at the end of the 1980s, these NGOs became redundant in their working style. Faced with the crises and inefficiencies of traditional government opponents, donors now want to work with NGOs in poverty reduction, good governance, and sustainable development programs (Igoe, 
2003). Social scientists, when faced with the crisis of old development models, have turned to NGOs' work for theoretical inspiration and political hope. In the past few years, NGOs have represented the instruments of fundamental development, democracy, and empowerment (Desai \& Preston, 2000).

The potential contribution of NGOs to rural areas stems from an increased concern for new development strategies in all spheres. A new technological agenda is urgently needed to meet the common challenges of sustainability and the increasing competitive pressures, which are caused by trade liberalization and regional integration (Alberto Alesina, 2001). New institutional configurations are needed because acting alone will not meet the contemporary challenges of development. They have to be structurally adapted and minimized especially if a more decentralized institutional approach is needed to respond more efficiently to local needs. Finally, if development programs contribute to the challenge of good governance, then they will also need to be accountable and participatory (Desai \& Preston, 2000).

\subsection{NGO Roles and Interests}

Non-Government Organization is the independent development organization within the existing ambit of the government. It is recognized as a non-profit corporation as it is operating on a non-profit basis and serving the displaced and poverty affected population voluntarily. There are various types of NGOs which exist and have a different scope of services and contributions, among which international NGOs deals with a variety of issues affecting people (Namara, 2009).

There are a variety of associations that have been characterized as individually owned from common society and then again classified as non-governmental associations is one of the consequences of the multifaceted nature of these NGOs. These NGOs emerged in the mid1980s as a result of the failure of both the market and state-based models of development solutions. The diversity of organizations that have been defined as members of civil society or as non-governmental organizations is certainly one of the causes for conceptual complexity from large international development agencies to informal savings groups in rural villages (King, 2013). There are some of the NGOs which use the directive strategy to support people in need (Namara, 2009). 


\section{EJMSS}

\section{Eurasian Journal of Management \& Social Sciences}

\subsection{An Explanation on Peace Winds Japan (PWJ)}

Kensuke Onishi is the CEO of Peace Winds Japan (PWJ), one of Japan's largest nongovernmental organizations. In 1996, he established the PWJ to carry out relief operations for internally displaced people in Syria in the Kurdish Autonomous Region of northern Iraq. Since 1996, PWJ has aided refugees, internally displaced people in Syria, disaster victims, and vulnerable populations in more than 15 countries, regardless of their ethnic origins, political affiliations, religions, or beliefs (Peace Japan, 2018).

Peace Winds was established as an international non-governmental organization with expertise in Japan, and the US responded to natural disasters and man-made crises worldwide. Peace Wind Japan and Peace Wind America work together with host countries, governments, nations, NGOs, U.N., foundations, the private sector, and individuals. Together the Peace Wind is prepared and responds with the "whole of society" approach. Intervention and mitigation programs have led to legislative and procedural changes, more networking and connectivity among respondents have resulted in better outcomes.

\subsubsection{Peace Winds}

- Responds rapidly to save lives and reduce suffering.

- Improves access to shelter, water, sanitation, and basic needs.

- Enables effective recovery, including livelihoods.

- Provides "whole of society" preparedness and response training.

Since 1996, Peace Winds Japan has targeted the neediest. The Middle East was the first recipients of aid, consisting of medical equipment, shelters, water, school construction, and livelihoods. For over twenty years, PWJ has helped displaced people and refugees in the world. The Peace Wind began in 2008, focusing on preparing and responding to natural disasters in the Asia Pacific. Since 2016, the two NGOs-Peace Winds-prepare and respond together to natural disasters and man-made crises around the world.

\subsubsection{Their Mission}

To strengthen the preparedness and response to natural disasters and man-made crises around the world through capacity building, coordination and collaboration among governments, militaries, NGOs, and the private sector (PWJ, 2016). 
- We provide timely humanitarian relief in emergencies to help people whose lives have been threatened by conflicts and natural disasters.

- We assist communities whose social foundations have been destroyed by providing rehabilitation and development cooperation for self-sustainability.

- We pursue conflict prevention and resolution through our field activities.

- We raise public awareness by disseminating information on assistance needs.

- We put forward proposals for improving the effectiveness of relief-providing mechanisms in society.

\subsection{Peace Winds Japan (PWJ) in Kurdistan}

Since its foundation in 1996, Peace Winds is dedicated to providing support to the people threatened by conflict, poverty or other disturbance. Headquartered in Japan, PWJ operates in the Middle East, Africa, and Asia. It has been assisting communities in the Middle East who are struggling due to conflicts and the crises in the region. The Peace Winds continue to have a long-standing presence in the Middle East. In 1996, the Peace Winds Japan was first to provide the first humanitarian aid programs in Iraq. For the past two decades, the Peace Winds have devoted their aid and rescue efforts in the region, including Afghanistan and Gaza. It provides food aid, housing construction, medical care, health services and sanitation, social welfare, education, and livelihood opportunities. Since 2012, the Peace Winds have focused on refugees and the people displaced and affected by increasing conflicts in Syria. Peace Winds takes care of WASH (Water and Sanitation) programs, housing and housing construction, education, and livelihood programs (Winds America, 2016).

The aid activities of PWJ are twofold: extraordinary humanitarian and disaster relief activities aimed at securing people's lives and targeting basic human needs and restructuring and development assistance for the renewal of self-sustaining livelihoods (Japan Platform, 2011). PWJ established its presence in Iraq in 1996 and since then has been conducting projects in various sectors such as education in the northern part of the country, capacity building training for teachers, health, water and sanitation and social welfare which continued even in the middle of the Iraq War in 2003. The PWJ Iraq program is now helping refugees, internally displaced people in Syria, and affected host communities through interventions in education, WASH, NFI, School Health Program, Shelter, Livelihood, and Infrastructure in Northern Iraq. The projects are financed by Japan 
Foreign Ministry, the Japan Platform, and UN agencies. The PWJ Iraq Program now functions in three governorates in northern Iraq: Arbil, Sulaymaniyah, Duhok, and the surrounding area. PWJ now has offices in Arbil, Duhok and Sulaymaniyah, Kurdistan (Peace Winds, 2013).

\subsection{PWJ Activities since the 2014 Crises}

\subsubsection{PWJ Range of Activities}

PWJ is mainly involved in various emergency and development activities in different sectors. All activities are coordinated with local authorities, clusters, the UN, and other humanitarian actors (Peace Japan, 2018). These activities can be elucidated as follows;

- Education: PWJ provided aids in the education sector through the construction of new schools including the renovation and expansion of existing schools so that children and communities can be provided with safe and sustainable access to education. PWJ is also active in the field of Emergency Education after the conflict in the country and neighboring countries, leading to the influx of large refugees (which also affects the host communities). The activities were selected after the evaluation of the needs and feasibility in coordination with the Ministry of Environment and Urbanism through the Ministry of National Education and Planning Office, EJCC, BRHA, KİK, UN, and other humanitarian actors. Educational interventions take place outside the camp and beneficiaries include refugees, internally displaced people in Syria, and affected host communities.

- Shelter and NFI: PWJ provides shelter-raising assistance to vulnerable refugees and internally displaced people and families to provide safe and durable shelters. The shelter aid is mostly in the camps. PWJ distributes NFI and emergency NFIs are distributed to new APOs and refugees in an emergency, and seasonal distributions such as in summer and winter, are distributed to help families cope with the harsh weather conditions. NFI distributions occur within and outside the camps as are needed.

- WASH: PWJ has been providing wash assistance to refugees, internally displaced people , and host community families to meet their water and sanitation needs 
inside and outside the camps. There are School Health Programs conducted by PWJ, Erbil, Duhok, and Sulaymaniyah for the affected school students. The program is carried out in cooperation with the Ministry of Health $(\mathrm{MOH})$. The program provides various medical treatments as well, such as Eye, ENT, Skin and Dental scanning, etc. Health education sessions are held in schools to raise awareness among children, teachers, and parents. Also, posters related to seasonal diseases and health are distributed to conscious schools.

- Infrastructure: PWJ provides infrastructural support to the camps through infrastructure rehabilitation projects such as camps, camping roads, electricity networks, basic infrastructure that improves drainage and camping conditions. The camp provides residents with health, logistics, and environmental benefits (Peace Japan, 2018).

\subsubsection{Some of the Latest Activities}

1. Securing Learning Environment for Syrian Refugee Children in Kurdistan Region of Iraq No More "Lost Generation" from the Syria Crisis - 2013.10.22 Erbil, Iraq Kurdistan Region (Kurdistan Government, 2013) - Peace Winds Japan (PWJ) is committed to the belief that education is always a priority. In cooperation with UNICEF, PWJ is building schools in four Syrian refugee camps in Iraq's Kurdistan Region (KRI) to create and develop a learning environment for Syrian refugee children. As the conflicts in Syria increased, millions of Syrians were displaced from the country and many fled to neighboring countries and escaped from fire and instability. After 15 August 2013, KRI suffered a massive Syrian refugee population, bringing the children of tens of thousands of Syrian schools to the KRI. For this reason, there was an urgent need in the education sector to intervene in this emergency, so these children would not be "out of school" for a significant time. In some of the newly established refugee camps, children are attending temporary schools, but the space for a large number of students is very limited and the building will not be sufficient for harsh weather conditions in the coming winter season (Kurdistan Government, 2013). The schools built by PWJ in partnership with UNICEF consist of sanitary facilities such as classes, toilets, sanitary areas, and a playground for outdoor activities. The design and layout aim to provide a safe and protective learning environment for students. To quote one of the mothers from 
Qamishli (Kawergosk Refugee Camp) in the Governorate of Erbil, "All my children were very good at school in Syria. As a mother, I must be sure that she continues to study without any gaps in the camp. At this moment we have lessons in temporary schools, but the prefabricated classrooms will be better when we consider the challenging winter season we will be facing very soon. The construction of PWJ's school in Kawergosk is expected to be completed by the end of this month. In coordination with the local authorities, UN agencies and other NGOs, PWJ will provide continued assistance in the education sector for these Syrian refugee children" (Peace Winds, 2013).

2. PWJ has started a school health program in Syrian refugee camps in Kurdistan region, Iraq - 2014.3.26

3. Iraq: Assessing the needs for the Internal Displaced Persons (internally displaced people) in northern Iraq 2015.9.9.

\subsection{Kurdistan Region and Syrian Crises}

\subsubsection{Internal Displacement and Refugee Status}

1. The main impact that the ISIL has on the Kurdistan region is the influx of internally displaced people of Syria and refugees. There are 1.4 million people seeking refuge in Iraq-Kurdistan. The military of ISIL is the fighting force of the Islamic State of Iraq and the Levant (ISIL). The total force size has been estimated from tens of thousands to over two hundred thousand. ISIL's armed forces grew quickly during 2014.

2. More than 750,000 refugees from Iraq go to Iraq-Kurdistan and a refugee camp in Domiz is hosting more than 50,000 Syrian refugees. According to the internally displaced people in Syria, some 200,000 Syrian Kurds have moved to IraqKurdistan, and the majority are children who are left behind to fight and protect their property with women and children.

3. Many ICIOCs have been able to stay with the family in Iraq-Kurdistan, especially in Erbil, to slightly reduce resource constraints in the region. The housing conditions in the Kurdistan region are terrible; many refugees and people living outside the camps live in churches, schools, and even on the crust of buildings, but the UN Refugee Agency is helping those who live outside the camp. 
4. The Yazidi and Christian Kurdish people are at the extreme risk from the ISID, by choosing the transformation or death presented to them which is emphasized by the Sinjar massacre and the threats to Christians in Mosul. Throughout the course of the ISIL's, there has been resistance from the Kurdish forces, with thousands of fighters fighting against ISIL, especially YPG and Peshmerga. There are about 250,000 Syrian refugees in the Iraqi Kurdistan Region (KRI), which accounts for 98 percent of all Syrian refugees in Iraq. This is in addition to the displaced persons (Internally Displaced People) in the 5 million countries in the region. Together, they account for 28 percent of the increase in the region's population. This represents a much higher proportion than the other recipient countries and represents a dramatic shift in the composition of society bringing with it enormous challenges of integration. This is since the internally displaced people in Syria come from different religious and ethnic backgrounds - Christians, Yazidis, Sunni Arabs, and Kurds. Integrating such different groups is extremely difficult. Prior to securing Syrian refugees and women and girls from the United Nations have been subjected to human rights violations, such as kidnapping, trafficking, torture, forced marriage, and other types of sexual and social sexual violence that lead to serious psychological distress. Since more than 75 percent of refugees and internally displaced people in Syria are women and children, they have made women responsible for protecting their children which increases their vulnerability. As can be expected, the economic and social impact of CRI on many people in a short period of time has been tremendous. A recent report by the World Bank concluded that the total cost of stabilization of refugee and internally displaced people inflow was at least $\$ 1.4$ billion for 2015. A report estimates (World Bank, 2015) that the decline in the rate of growth of the KRI has fallen to 5 percent from 2013 to 2014, as the financial crisis continues to add to the refugee and internally displaced people crisis, driven by oil price decline and inadequate budget transfers from Baghdad. All indicators show that the decline is even higher in 2015 . The poverty rate rose to 12.5 percent in 2014 from 3.5 percent in 2001.

\section{Research Methodology}

The qualitative research method is used for the current study. The tool of data collection is interview schedule which contains eight (8) different questions, further divided into two parts- the first part is the demographic and background experience questions (Name, 


\section{EJMSS}

Eurasian Journal of Management \& Social Sciences

Gender, Education, and Current Position). The second part poses questions about activity rewards (over three to five years), creativity and innovation which the NGOs have done so far, what are the long-term objectives to be completed, what are the factors which can make the NGO different from a similar organization, does PWJ NGOs also deals police regarding the refugees, is there any development in the PWJ NGOs objectives. What are the disadvantages or challenges your institution experienced when operating in camps of refuges and with government and how PWJ NGOs describe organization's culture/environment? The study questionnaire is organized based on the information that has been given by the report of (Dinish Refugee Council, 2015) which discusses the role of NGOs being there over the years and (Bebbington \& Biekart, 2007).

Furthermore, the selected sample research population for the study were three top members of the PWJ NGOs- project coordinator, deputy project manager, and direct reporter. Phase to phase interview has been executed based on the research structure and prepared questions were asked to the selected respondents.

\section{Data Analysis}

This study is analyzing the qualitative data which depends on the interview, which is figured out by the researcher consisting of eight (8) different questions. Each interview is started by introducing the researcher and try to analyze their answers and how this will help the readers.

\subsection{First Interview}

Project coordinator of the Peace Winds in Japan (NGO), named (Hoshmand L. Fatehy). He has the responsibility of a group of P.W.J which provides (NFI, non-food item), WASH, Shelters, health, food, education, livelihood and cash for work (those projects are funded by the Japan government and donors).

1. What is your activity reward over $3 / 5$ years?

Hoshmand L. Fatehy-Project Coordinator of the Peace Winds in Japan (NGO)

Answer: "Generally helping all the people affected by war, conflicts and natural disasters in most parts of Kurdistan. Making them stand on their feet providing them with every 
basic need. It is about this tension surrounding the middle east especially Iraq and Kurdistan especially, Kurdish people (Internally Displaced People) and refugees who came from Syria. All of them were affected by ISIS (Islamic State of Iraq and Syria)". His response shows that several welfare activities were conducted which helped the beneficiaries to rehabilitate.

Bareza Mustafa Sattar- Project Assistant in P.W.J Organization.

Answer: Promotion from field supervisor to project assistant. In her response, she mentioned that her position has changed but did not mention any specific project or activities.

Rawa Othman Al-mufti- Progress \& Productivity Direct Reports Supervisor of the PWJ.

Answer: Operator in Sulaymaniyah for 7 months and serving those people who are displaced and affected by ISIS and providing for their urgent needs. He didn't mention any rewards he only focused on his main duty in Sulaymaniyah and the importance of serving people emergencies that were displaced because of the ISIS threat.

2. What are the creative and innovative things that you have done in the last $3 / 5$ years?

Hoshmand L. Fatehy Project- Coordinator of the Peace Winds in Japan (NGO).

Answer: "Day by the day after getting the experience you will find new ways and tactics to deliver what is in your hand to the right beneficiaries. During distributions and while implementing projects you will need to be creative and innovative so that by the ending of the project you will make the donor and the refugee happy." He responds as a responsible and active executor in which the employees feel responsible for their work. He has special projects and keeps account of what is needed for people in the camps and making all these a project and raising funds from the donors to help refugees.

Bareza Mustafa Sattar- Project Assistant in P.W.J Organization.

Answer: "Little can we be creative in the humanitarian field considering our work is emergency and nothing is preplanned. Mostly my creativity is used for administrative and relations related tasks." In her response, it shows that in this NGO nothing is preplanned and it refers to the emergency events such as natural disasters and crisis, war. 


\section{EJMSS}

Eurasian Journal of Management \& Social Sciences

Rawa Othman Al-mufti- Progress \& Productivity Direct Reports Supervisor of the PWJ.

Answer: In the last three years, I have executed many projects perfectly". As he experienced in the past three years he said that many successful projects have been implemented with a good result. In the last three years, this NGO has spent 15,366,062.5 USD in Iraq during the ISIS war, BC, JHM, (2014).

3. What are some of the long-term objectives you would like to see to be completed?

Hoshmand L. Fatehy- Project Coordinator is trying to get all the refugees and internally displaced people in Syria. "The vulnerable host communities are the main target of the organization. But for the long-term, our objective is to build a safe shelter for all Syrian refugees in Kurdistan without any discrimination."

Bareza Mustafa Sattar- Project Assistant talks about an overall improvement of the refugee lives here in the region. In her response, she mentions about how they work for making refugee life better in the Kurdistan region.

Rawa Othman Al-mufti- Progress \& Productivity Direct Reports Supervisor talks about receiving all help and donations for the people who are displaced and refugees and the distribution is done without any discrimination. In his response, he mentions that PW.J strives to utilize all the resources they receive in an efficient and effective way to make an immense influence to improve lives and the condition of the people they assist.

\section{What makes this NGO different from a similar organization?}

Project Coordinator of the Peace Winds in Japan (NGO), "Our organization is trying to collect donations from all over the world. We are not relying on one source or any single country. The difference between PWJ and other such organizations is that we see ourselves as a bridge between donors and refugees from all the countries." His response shows that this NGO is creating the right connection with many donors and sources around the world.

Project Assistant in PWJ Organization, "It is small in size of employees, yet the great number of projects and goals have been already achieved". In her response, she is revealing that PWJ is involved in many emergency and development activities in different sectors. 
Progress \& Productivity Direct Reports Supervisor of the PWJ, "Our NGO is respected within all communities and minorities and all religions without discrimination and anywhere people need help, our Organization will be there". It shows that they are serving people with responsibility under emergency humanitarian relief, reconstruction, and development assistance all over the world.

5. Does your NGO have the policy for dealing with refugees?

Hoshmand L. Fatehy, "All NGOs have policies and rules for dealing with beneficiaries and of course, our Organization has a very strong code of conduct regulations, which tells us what to do and how to behave with refugees. PWJ NGOs have a code of conduct that is written and guides us on how employees have to work and what they have to do with refugees during their work. Also there are training courses which teach them how to treat people in the camps, they all have to consider situations in refugee lives, their health, psychology and etc. during their duties in the camps.

Bareza Mustafa Sattar, "Yes, the NGO in all its operational fields are dedicated to supporting people in distress including refugees". In her response, it shows that they provide timely humanitarian support in emergencies to help those people who are affected by man-made war, conflict, and natural disaster. Also, in the PWJ organization, regular training of the employees takes place and they are taught the process of dealing with the refugees in difficult circumstances.

Rawa Othman Al-mufti, “Our organization has its own regular written rules which guide employee on how to serve people inside camps and how to treat them. PWJ has its own code of conduct".

6. The PWJ NGO's objectives changed in the last 5 years?

Mr. Fatehy said, "Of course, every organization sets the goal and objectives according to the situations and places, our organization started with some goals five years before, but after the ISIS crisis, our objectives have changed accordingly with the prevailing conditions and situations fo the Kurdistan region."

Ms. Bareza said, "No, but rather the NGO has more projects that better serve the objective of the matter of NGO". 
Al-mufti mentions that "our objectives will be changed according to the situation. There is no fixed long-term objective, each objective might be changed with conditions, and emergency situations."

7. What are the disadvantages or challenges have your organization experienced when operating in camps of refugees and with the government?

Hoshmand L. Fatehy mentioned that, "If we talk about challenges, yes, we have a lot of challenges especially in the camps due to tremendous demands of basic needs, and a crowd of people but with the help of the government and other organizations we could accept the challenges and reaching our goals perfectly. We could see clearly that a good relationship exists with the government and there is cooperation with each other, which provides land facilities, communications, transportations, etc. But with refugees, surely there will be many problems and disadvantages which they face because of crowds and religious as well as cultural diversity".

Bareza Mustafa Sattar, "The response strategy of the government as a whole is not planned and well-organized one, it's lagging and not well-studied. This makes the response of NGOs also slow. Government is not cooperative which can have an adverse effects on NGOs working in the region and with refugees."

Rawa Othman Al-mufti, "With the government, we have cooperation and coalition. They will help us and provide us more facilities, but with refugees, there are many problems we face because there is a diverse population in the camp. The huge numbers of refugees in camps make the control difficult sometimes. Another crisis inside the camps is when sometimes they fight with each other."

8. How would you describe organizations' culture/environment?

Project Coordinator of the Peace Winds in Japan (NGO) said that "Each organization has its own environment and culture. PWJ has a very friendly and open environment and we can say our staff is working in a comfortable situation which is very important to make them focus on their daily tasks. The organization culture like a system of shared supposition beliefs and values which guides how people should behave in the institution, this process has a strong influence on people in the NGO and provide how they perform their jobs, each 
organization has its own unique culture in which guidelines for the behavior of the members of the organization are clearly mentioned."

Project Assistant in PWJ Organization, "An environment in which there is cooperation, all teams work hand in hand to serve the goals of the organization."

Progress \& Productivity Direct Reports Supervisor of the PWJ, "Everyone in the organization is helping each other. We notice that both NGO and the government are in good relation."

\section{Findings}

The findings reflect that the development of the refugee camps can be done with a wellplanned strategy. In order to increase their humanitarian and social activities in camps for all refugees in general as well as on a larger scale, which answers the first study question about how Peace Winds Japan NGO affected internally displaced people in Syria life during 2014-2017.

Furthermore, the study outcome figured out that the employees of the PWJ NGO need to take more courses on developing information about the organizational culture/environment. The lack of knowledge was obvious and awareness is considered as an important key reason to attain success and also for maintenance of the organization.

During their services and helping the refugees, Peace Wind Japan concentrated more on internally displaced people in Syria living in camps rather than outside of the camps. The response was collected from the population residing inside the camps, who are dependent, like families, children, women, and teenagers. The external refugees of the camps can manage and protect their life. Peace Wind Japan maintains the objective of improving refugee lives. The "code of conduct" for any NGO is also one of the important fact which is to be kept in mind while operating, which answers the study question 4.

In the last research question, Peace Wind Japan's relationship with the government is in good shape and the cooperation between Non-governmental Organizations, especially PWJ and regional Government to serve refugees and providing for the needs during the ISIS conflict during 2014-2017 is well established. PWJ's activities include providing for the necessities like shelter, food, education and etc. The study evaluated important resources 
for gaining information such as interviewing NGO's employees which helped to complete this study in an efficient manner.

\section{Conclusion}

In this research, I discussed the Non-Governmental Organization's role and difficulties they face while working in Kurdistan region of Iraq, especially when the region was surrounded by tension and crisis for the last three years. Non-governmental Organization is working anywhere around the world, which is humanitarian relief, devoted to supporting those people who are under threat or are displaced because of man-made war, conflict, natural disasters, and other turmoils. With their headquarters in their basic countries, they are operational in many parts of the world. I also selected one of the NGOs (Peace Winds Japan) to discuss their activities and objectives. The mission of this NGO is to provide timely humanitarian relief in a sudden unforeseen crisis, to protect and help those people are in crisis due to any reasons, such as natural disasters, war, or mass destruction. The purpose of this study was also to find out the effectiveness of Peace Winds Japan programs toward internally displaced people in Syria in Kurdistan. In conclusion, I would like to mention some important points; First, the cooperation between Non-governmental Organizations, especially PWJ and regional Government to serve refugees and providing for the needs during the ISIS conflict during 2014-2017 is well established. PWJ's activities include providing for the necessities like shelter, food, education and etc.

Through the interviews conducted in the Peace Wind Japan office in Erbil with three senior managers, it seems that PWJ programs are effective, especially in providing high-quality shelters to the refugees. However, they face some difficulties in implementing their programs within the camp such as registering refugees and following their movement as well as communication between refugees who are afraid of unfair treatment. These difficulties explain why for the most part of their programs they focused on camps activities rather than internally displaced people in Syria spread all over the camps. As a result, this research found out that there are some basic requirements which need to be done for the sake of developing the strategy of dealing and helping refugees. In addition, the study also figured out that the employees of the PWJ NGO need to take more courses on developing the information about the organizational culture/environment in the context of their answers where the lack of knowledge was obvious and awareness is considered as an important key reason to attain success and also for maintenance of the organization. The 
relationship with the government is in good shape and the cooperation between NGOs and government is a very important step to be able to work and implement one's policies and programs effectively. The "code of conduct" for any NGO is also one of the important facts which is to be kept in mind while operating.

\section{References}

Alberto Alesina, E. G. (2001). Why doesn't the united states have a european-style welfare state? Brookings Papers on Economic Activity, 32, 188-189.

Bebbington, A., \& Biekart, K. (2007). Northern NGOs and indigenous organizations. Rotterdam: Synthesis study of a joint research project initiated and supported by Ibis, Hivos,.

Desai, V., \& Preston, I. (2000). Urban grassroots nongovernmental organizations in bombay: A suggested typology. Sage.

Dinish Refugee Council. (2015). Access, possibility of protection, security and humanitarian. Copenhagen: Danish Immigration Service.

Igoe, J. (2003). Scaling up civil society: donor money, NGOs and the pastoralist land rights movement in Tanzania. Blackwell.

Japan Platform. (2011, 11). Japan Platform. Retrieved from www.japanplatform.org: https://www.japanplatform.org/E/programs/syria.html

King, S. (2013). Can NGOs cultivate supportive conditions for social democratic development?

Kurdistan Government, R. (2013, 10 21). Kurdistan Regional Government. Retrieved from http://cabinet.gov.krd

Namara, R. B. (2009). NGOs, poverty reduction and social exclusion Uganda. Institute of Social Studies, 10.

Peace Japan, W. (2018, 2 13). Peace Winds Japan. Retrieved from https://peacewinds.org/en/about.html: https://peace-winds.org/en/about.html

Peace Winds. (2013). Peace Winds. Retrieved from peace-winds.org: https://peacewinds.org/en/activity.html

Spark. (2018, August 9). Retrieved from Spark-Online: http://www.sparkonline.org/kurdistan-region-iraq-role-ngos-stability/

Winds America, P. (2016). Peace Winds America. Retrieved from peacewindsamerica.org: http://peacewindsamerica.org/peace-winds-supportmiddle-east/

World Bank. (2015, 12 2). World Bank. Retrieved from http://www.worldbank.org: http://www.worldbank.org/en/news/press-release/2015/02/12/kurdistan-regioniraq-stabilize-economy 